\title{
Extraction and determination of flavonoids in Carthamus tinctorius
}

https://doi.org/10.1515/chem-2018-0119

received December 7, 2018; accepted May 14, 2018.

Abstract: Carthamus tinctorius L. also known as: Acanthopanax safflower, red blue flower, it is the Compositae genus of safflower. The active ingredient of Chinese medicine safflower are flavonoids. In order to optimize the extraction method of total flavonoids, extraction with an ultrasonic extraction method, and ultraviolet spectrophotometry was used to determine the content. The results show that, the content of flavonoids in Carthamus tinctorius was $20.6 \mathrm{mg} / \mathrm{g}$. Compared with the traditional methods, the ultrasonic extraction method can shorten extraction time and reduce energy consumption.

Keywords: Safflower flavonoids; Ultraviolet spectrophotometer; Extraction.

\section{Introduction}

\subsection{Carthamus tinctorius $L$.}

Carthamus tinctorius L. is an annual herb dicotyledonous plant, height 90 120cm [1]. Also known as: Acanthopanax safflower, red blue flower, it is the Compositae genus of safflower. The whole plant is hairless [2].

\subsection{Main chemical constituents of Carthamus tinctorius}

Using current scientific and technological means, the many chemical constituents in Carthamus tinctorius have

\footnotetext{
*Corresponding author: Miao Yu, Center of Research and Development on Life Sciences and Environmental Sciences, Harbin University of Commerce, Harbin, 150000, P.R. China, E-mail: Yumia0913@163.com

Yubin Ji, Shizheng Guo: Center of Research and Development on Life Sciences and Environmental Sciences, Harbin University of Commerce, Harbin, 150000, P.R. China

Bing Wang: School of Food Engineering, Harbin University of Commerce, Harbin, 150000, P.R. China
}

been determined. The major components are pigments, flavonoids, phenolic acids, fatty acids, essential oils, alkynes, and other components. Pigment is divided into safflower yellow pigment and red pigment. Flavonoids are mainly composed of the glycosides derived from shannesol and quercetin, safflower yellow A, hydroxysafflor yellow $A$, red pigment, apigenin, quercetin, rutin, myricetin etc. [3]. In addition, there are flavonoids such as safflower glucoside and safflower glycoside and so on. Other classes of compounds have been determined such as syringin, ferulicacid, $p$-hydroxycinnamic acid, daucosterol, palmitic acid and stearic acid mixture, isovaleric acid, $\mathrm{p}$-coumaric acid, hydroxy benzoyl coumaric acid anhydride, apigenin, sixteen alkyl acid ester etc. Dark yellow flowers contain safflower glycosides; orange red flowers contain safflower glycoside and quinone glucoside; pale yellow flowers contain safflower glucoside and trace safflower glycoside. The change in the colour of the corolla is due to changes in these constituents [4-8]

\subsection{Method for extracting safflower total flavone and determination of total flavonoids}

Reflux extraction method: This method has high extraction efficiency and shortens extraction time. This method shall not be applied to thermally unstable or volatile components [9]. Microwave extraction: This method has the advantages of simple operation, high extraction rate, accurate, rapid and friendly environment [10]. Ultrasonic extraction: This extraction method without special equipment is easy to operate and saves time. Compared with the traditional solvent extraction method, the time is much shorter [11]. UV spectrophotometry: Within a certain wavelength range, the total flavonoids of safflower have specific UV absorption peaks. There are characteristic absorption peaks at $330 \mathrm{~nm}$. Rutin is used as the control substance, detection at $500 \mathrm{~nm}$ wavelength and the standard curve is made to calculate the total flavonoids of Carthamus tinctorius [12]

Liquid chromatography: Chromatographic column: RP-C18 $(250 \mathrm{~mm} \times 4.6 \mathrm{~mm}, 5 \mu \mathrm{m})$; detection 
wavelength:265.8nm; mobile phase: acetonitrile-waterglacial acetic acid (19.5:80.5:0.5) $(\mathrm{pH}=3.8)$; volume flow: $1.0 \mathrm{ml} / \mathrm{min}$; temperature: $20^{\circ} \mathrm{C}$. The detector is usually a UV detector or fluorescence detector that can analyze the total content of flavonoids in safflower [13].

\subsection{Pharmacological action of flavonoids in safflower}

Using modern science and technology to study the active ingredients of safflower, it is indicated that safflower has a very wide range of pharmacological effects, which can be summarized as follows [14].

The extract of safflower has protective effect on the heart system, which can improve myocardial ischemia, reduce the area of myocardial infarction, improve the heart rate, and supply oxygen to the myocardium [15]. Safflower can play a role in the expansion of blood vessels, the action of safflower dilating blood vessel is related to the function of blood vessel and the dosage of the medicine. Its vasoconstrictor effect is achieved by reducing $\mathrm{Ca}^{2+}$ and inhibiting influx [16]. The total flavones extracted from Carthamus tinctorius had different hypotensive effects on the experimental animals [17-18]. The average blood pressure dropped at about $20 \mathrm{mmHg}$ and lasted for about 30 minutes [19]. The extract of Carthamus tinctorius extract can inhibit the platelet aggregation induced by ADP, and has obvious depolymerization effect on ADP aggregated platelets. These effects of safflower flavonoids were enhanced with increasing doses [20]. Safflower can regulate a variety of inflammatory response-related growth factors and cell adhesion molecules gene expression. Therefore, it has a certain anti-inflammatory effect [21].

\section{Experiment}

\subsection{Experimental instruments and drugs}

\subsubsection{Experimental instrument}

CP224S type analytical balance, UV spectrophotometer, electric constant temperature water bath pot, numerical control ultrasonic cleaner.

\subsubsection{Experimental drug}

Rutin reference materials, Safflower, anhydrous ethanol, sodium hydroxide, sodium nitrite, aluminum nitrate. (The above reagents are pure and water is distilled water.)

\subsection{Experiment content}

\subsubsection{Preparation of reference and test samples}

1. Control sample preparation: $5 \mathrm{mg}$ of rutin, $50 \mathrm{ml}$ volumetric flask, add $60 \%$ alcohol, dissolved in a water bath heat, cooling, adding $60 \%$ ethanol to the scale, shake, made a standard solution containing $0.1 \mathrm{mg} / \mathrm{ml}$ rutin.

2. Sample preparation: the powder $0.5 \mathrm{~g}$, a conical flask with stopper precision by adding $60 \%$ ethanol $50 \mathrm{ml}$, weighed, ultrasonic treatment (power 300W, frequency 50kHz) 40 minutes, put in the cold, weigh lose weight, make up $60 \%$ of the ethanol shake, filtration, get the test solution.

\subsection{Linear relation}

Precise amounts of Rutin in solution of $1 \mathrm{ml}, 2 \mathrm{ml}, 3 \mathrm{ml}, 4 \mathrm{ml}$, $5 \mathrm{ml}, 6 \mathrm{ml}, 25 \mathrm{ml}$ were placed in the flask, the addition of $60 \%$ ethanol solution with $6 \mathrm{ml}, 0.3 \mathrm{ml}$ sodium nitrate, mixing, placed 6 minutes, plus $10 \% \mathrm{ml} 0.3$ aluminum nitrate, shake for 6 minutes, adding sodium hydroxide 4 $\mathrm{ml}$, and $60 \%$ ethanol solution was diluted to the scale, shake for 15 minutes, with the corresponding reagent blank, at 500nm wavelength, with UV spectrophotometer to measure the absorbance.

\subsection{Methodological investigation}

1. Precision experiment: Taking rutin solution $3 \mathrm{ml}$ in $25 \mathrm{ml}$ flask, add $60 \% 6 \mathrm{ml}$ ethanol solution, sodium nitrate solution with $0.3 \mathrm{ml}$, mixing, placed $6 \mathrm{~min}$, plus $10 \% 0.3 \mathrm{ml}$ aluminum nitrate, shake for 6 minutes, plus $4 \mathrm{ml} \mathrm{NaOH}$, add $60 \%$ ethanol to the scale, shake, placing 15 minutes, with the corresponding reagent blank at 500nm wavelength, with UV spectrophotometer to measure the absorbance, repeat for 6 times.

2. Stability test: Take the test solution $3 \mathrm{ml}$ in $25 \mathrm{ml}$ flask, adding $60 \%$ ethanol for $6 \mathrm{ml}$, with $0.3 \mathrm{ml}$ sodium nitrate solution, mixing, placed 6 minutes, plus 10\% $0.3 \mathrm{ml}$ aluminium nitrate, shake for 6 minutes, plus 
$4 \mathrm{ml} \mathrm{NaOH}$, add $60 \%$ ethanol to the scale, shake well. For 15 minutes, with the corresponding reagent blank at the wavelength of $500 \mathrm{~nm}$, with UV spectrophotometric absorbance meter. In 60min, the absorbance was measured every 10 minutes.

3. Repeated experiment: The samples were weighed accurately and independently, 5 copies under the “2.2.3(2)" item.

4. Recovery test:5 samples with known content were added accurately, and a certain amount of standard solution $25 \mathrm{ml}(0.424 \mathrm{mg} / \mathrm{ml})$ was added accurately.

5. Determination of safflower content: A prepared sample solution has been prepared. Under the 2.2.3(2) method, $60 \%$ ethanol was used as blank solution, and was measured at the wavelength of 500nm. Repeated determinations were performed 3 times.3.

Ethical approval: The conducted research is not related to either human or animals use.

\section{Results}

\subsection{Linear relation}

To control the concentration of the solution (g) as the abscissa, the absorbance $(\mathrm{Y})$ as the ordinate, standard curve to calculate the regression equation: $\mathrm{Y}=0.0135 \mathrm{X}+0.0115(\mathrm{r}=0.999)$ showed that rutin showed a good linear relationship with absorbance in the range of 8.208 to $49.248 \mu$ g (Figure 1 ).

\subsection{Methodological investigation}

1. Precision experiment: Through the above experiments, RSD was $0.41 \%$, and the result showed that the rutin standard solution had good precision within 1 hours (Table 1).

2. Stability test: Through the above experiments, RSD was $0.48 \%$. The results showed that the total flavonoids in the sample solution were basically stable in 1 hour (Table 2).

3. Repeated experiment: RSD was $1.85 \%$. The result showed that the method was reproducible (Table 3).

4. Recovery test: The recovery rate was calculated according to law (Table 4).

5. Determination of safflower content: The results were as follows (Table 5).

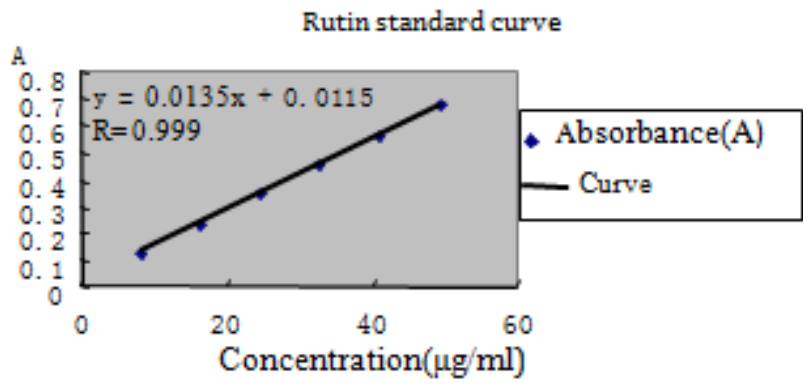

Figure 1: Standard curve of rutin.

Table 1: Results of precision experiment. $(n=6)$.

\begin{tabular}{lllll}
\hline NO. & A & S & X & RSD(\%) \\
\hline 1 & 0.345 & & & \\
2 & 0.346 & & & \\
3 & 0.345 & 0.001414 & 0.345 & 0.41 \\
4 & 0.347 & & & \\
5 & 0.344 & & & \\
6 & 0.343 & & & \\
\hline
\end{tabular}

Table 2: Stability test results. $(n=6)$.

\begin{tabular}{lllll}
\hline NO. & A & S & X & RSD(\%) \\
\hline 1 & 0.357 & & & \\
2 & 0.359 & & & \\
3 & 0.361 & 0.001722 & 0.360 & 0.48 \\
4 & 0.360 & & & \\
5 & 0.362 & & & \\
6 & 0.360 & & & \\
\hline
\end{tabular}

Table 3: Experimental results of repeated experimental solution.

\begin{tabular}{lllll}
\hline NO. & A & S & X & RSD\% \\
\hline 1 & 0.362 & & & \\
2 & 0.358 & & & \\
3 & 0.348 & 0.006565 & 0.355 & 1.85 \\
4 & 0.353 & & & \\
5 & 0.346 & & & \\
6 & 0.360 & & & \\
\hline
\end{tabular}

Table 4: Experimental results of recovery of total flavonoids in Carthamus tinctorius.

\begin{tabular}{lllllll}
\hline & $\begin{array}{l}\text { Sample } \\
\text { content } \\
\text { (mg) }\end{array}$ & $\begin{array}{l}\text { Scalar } \\
\text { (mg) }\end{array}$ & $\begin{array}{l}\text { Measured } \\
\text { quantity } \\
\text { (mg) }\end{array}$ & $\begin{array}{l}\text { Rate of } \\
\text { recovery } \\
(\%)\end{array}$ & $\begin{array}{l}\text { Average } \\
\text { recovery } \\
(\%)\end{array}$ & RSD(\%) \\
\hline 1 & 10.3 & 10.6 & 20.4 & 95.28 & & \\
2 & 10.2 & 10.6 & 20.5 & 97.16 & & \\
3 & 10.3 & 10.6 & 20.8 & 99.05 & 97.61 & 2.17 \\
4 & 10.2 & 10.6 & 20.6 & 98.11 & & \\
5 & 10.1 & 10.6 & 20.7 & 98.47 & & \\
\hline
\end{tabular}


Table 5: The content of total flavonoids in Carthamus tinctorius.

\begin{tabular}{llll}
\hline NO. & A & C(mg/g) & X(mg/g) \\
\hline 1 & 0.347 & 20.63 & \\
2 & 0.345 & 20.61 & 20.6 \\
3 & 0.341 & 20.58 & \\
\hline
\end{tabular}

Using the rutin standard solution of $0.1 \mathrm{mg} / \mathrm{ml}$ which we have prepared, it has a good linear relationship with absorbance in the range of 8.208 to $49.248 \mu \mathrm{g}$, and the regression equation is $\mathrm{Y}=0.0135 \mathrm{X}+0.0115(\mathrm{r}=0.999)$. We can extract the total flavonoids from Carthamus tinctorius by using the extraction technique, and prepare the solution for the sample. The total flavonoids in Carthamus tinctorius were determined by UV spectrophotometry. After a series of methodological investigations on the tested products, the content of safflower was determined 3 times, respectively, 20.63, 20.61 and $20.58 \mathrm{mg} / \mathrm{g}$, with an average value of $20.6 \mathrm{mg} / \mathrm{g}$. The content of flavonoids in Carthamus tinctorius was obtained.

\section{Discussion}

1. Selection of extraction methods: There are many ways to extract flavonoids, Often used are the reflux extraction method, microwave extraction method and ultrasonic extraction method. In this experiment, ultrasonic extraction was selected. Compared with the traditional method, the ultrasonic extraction method has the advantage of no special equipment, simple operation and easy realization. The traditional reflow extraction method usually takes 2 hours, While the ultrasonic extraction method only takes 40 minutes to achieve the extraction rate. This method greatly reduces the time taken for extraction.

2. Factors affecting UV spectrophotometer include temperature, electromagnetic fields, dust, vibration, etc. In this experiment, the temperature of the laboratory is low, which makes the temperature the greatest environmental factor affecting the reading of this experiment. The sensitivity of UV spectrophotometer decreases with low temperature.

To sum up, this study has scientific and reliable theoretical basis, which lays a foundation for optimization of the extraction method of total flavonoids in red flowers.

Acknowledgments: This work is supported by Postdoctoral foundation of China (2015M581467); Natural
Science Foundation of Heilongjiang Province (D201138); Heilongjiang Postdoctoral special Foundation (LBHTZ1613); Heilongjiang Postdoctoral Grant (LBH-Z15107); The Scientific Research Team Program of Harbin University of Commerce (2016TD002); Harbin Special Foundation for Young Technological Innovative Talented Person (2013RFQXJ150); The Scientific Research Program of Harbin University of Commerce (17XN061).

Conflict of interest: Authors state no conflict of interest.

\section{References}

[1] Singh S., Boote K.J., Angadi S.V., Grover K., Begna S., Auld D., Adapting the CROPGRO Model to Simulate Growth and Yield of Spring Safflower in Semiarid Conditions, Agron. J., 2016, 108, 64-72.

[2] Zhao L., Du Z., Li L.., Research progress on Safflower, Chin. J. Chin. Med., 2007, 3, 75-77.

[3] Li X., Hu X., Dai Z., Zhang Y., Liang H., Lin R., Study on chemical constituents of Carthamus tinctorius, Chin. Med. Herb., 2012, 35, 1616-1619.

[4] Xiao Y., Cui M., Li Y., Chemical constituents of safflower, J. Wuhan Univ. Technol., 2014, 36, 15-17.

[5] He J., Chen Z., Yang Y., Study on chemical constituents of water extracts from Carthamus tinctorius, J. Chin. Pharm. Sci, 2014, 49, 455-458.

[6] Zhao J.F., Liu J., Guo Y., Liu Q., Dai Z., Ma S.C., Lin R.C., Chemical constituents from safflower injection and their bioactivity, Chin. J. Chin. Mater. Med., 2014, 39, 3102-3106.

[7] Wang R., Yang B., Research progress of chemical constituents and quality standard of safflower, Chinese Journal of experimental Chinese Journal of pharmacology, 2007,13, 65-69.

[8] Akram M., Iqbal M., Daniyal M., Khan A.U., Awareness and current knowledge of breast cancer, Biol Res., 2017, 50, 33.

[9] Zong X., Shi D., Zhang H., Li B., Li L., Song Y., Effects of different solvents and extraction methods on antioxidant activity of safflower extract, Guizhou Agricultural Sciences, 2012, 40, 44-46.

[10] Li N., Lu X., Study on microwave extraction of safflower flavones, China brewing, 2010, 05, 100-109.

[11] Xiong Y., Xu M., Liu J., Li S., Zhang Ch., Chen X., Optimization of ultrasonic extraction process of total flavones of Cerasus tomentosa, Chinese Journal of experimental Chinese medicine, 2008, 18, 29-31.

[12] Zhou H., Zhao Ch., Sun P., Tong W., Ye X., Xiao Y., Study on extraction technology, white variation of total safflower flavone, J. Chengdu Univ. Trad. Chin. Med., 2015, 38, 27-31.

[13] Zheng Y., Chen L., Feng S., Huang X., Liu Y., Chen X., Di D., To investigate the spectroscopy and spectral analysis method for determination of total flavonoid content in olive leaves, 2011, 31, 547-550.

[14] Delshad E., Yousefi M., Sasannezhad P., Rakhshandeh H., Ayati Z., Medical uses of Carthamus tinctorius L. (Safflower): a comprehensive review from Traditional Medicine to Modern Medicine, Electron. Physician, 2018, 10, 6672-6681. 
[15] Bao S., Cui K., Zhao S., The preliminary results of. Pharmaceutical effects of safflower oil on mice with experimental hypercholesterolemia bulletin, 1984, 19, 59.

[16] Cao Y.-X., Zhang X., Zhang C., He Y., Ma Y., On the effect of safflower extract on renal ischemia reperfusion injury, 2011, 25, 26-28.

[17] Maneesai P., Prasarttong P., Bunbupha S., Synergistic Antihypertensive Effect of Carthamus tinctorius L. Extract and Captopril in l-NAME-Induced Hypertensive Rats via Restoration of eNOS and AT1R Expression Nutrients, 2016 Mar; 8, 122.

[18] Zhang T.-X., Jing H., Mai W.-L., Liu H., Niu C.-Q., Research on the mechanism of safflower injection decreased medicine of arterial blood pressure in rabbits, Lishizhen Med. Mater. Med. Res., 2010, 21, 138-139.

[19] Guo X., Yang X., Wang Y., Study on anticoagulant effect of Compound Safflower Yellow Pigment, Xinjiang Agric. Sci., 2012, 49, 1759-1763.

[20] Yang D., Ma Y., Effect of Safflower on electrical activity of uterine smooth muscle in rats, J. Gansu College Trad. Chin. Med., 2010, 17, 13. 